\title{
Fracture Strength at Low Temperature in Notched Steel Specimens Preloaded at Room Temperature*
}

\author{
By Morihiko Nakamura**
}

\begin{abstract}
It is well known that plastic deformation at the tip of a notch or defect influences the brittle fracture in structural steels. Recently the COD (crack opening displacement) concept has come to be applied for the brittle fracture initiation of low and medium strength steels, attaching great importance to research for the influence of the condition at the tip of a notch on the brittle fracture initiation of steel. In this study, the effect of preloading on the fracture strength was studied using notched specimens of low strength structural steel (SM 50). Standard Charpy V specimens were preloaded up to a general yield load by 3 or 4-point loading and then fractured by 3 or 4-point loading at various strain rates at liquid nitrogen temperature. The influence of preloading appeared in specimens which had been preloaded so that their notched surface might be subjected to tensile stress, and their fracture loads tended to increase with preload. However, the specimens which had been preloaded so that their notched surface might be subjected to compressive stress, was not apparently influenced by preloading. The above-mentioned results indicate that the residual stress as well as the plastic deformation at the root of a notch influences the fracture strength of the notched specimens.
\end{abstract}

(Received April 5, 1973)

\section{Introduction}

A plastic deformation zone is formed in the vicinity of the tip of a crack, even when cracked steel specimens are not loaded up to a general yield load ${ }^{(1)}$. It is thought that the behavior of a plastic zone is closely related to the unstable fracture in steels. Crack Opening Displacement (COD) is based on the concept that unstable fracture initiates in cracked structures when the relative movement of the two crack faces at the crack tip due to the increase of plastic zone size takes a critical value ${ }^{(2)-(5)}$. However, many problems remain about the critical COD criterion, e.g. why there is a critical relative movement of the two crack faces, what defines a critical value and so on. Therefore, it is important to clarify the influence of plastic zone in the vicinity of the crack tip on the initiation of brittle fracture in steels.

Preloading of notched specimens leads to the formation of a plastic zone at the tip of a notch, which influences the initiation of unstable fracture. Some workers have experimentally revealed the influences of preloading on the fracture strength of notched high strength steel specimens and it is known that preloading at higher temperatures increases the brittle fracture strength $^{(6)(7)}$. This improvement of toughness is attributed to the presence of the residual stress at the root of a notch. It is also known that if the welded steel is preloaded opposite to the residual stress caused by welding, its fracture strength is improved ${ }^{(8)}$. Therefore, when pressure vessels are tested under hydrostatic pressure at higher temperatures than that used in practice, it is expected that the brittle fracture strength is improved ${ }^{(9)}$. A modified critical COD criterion proposed by Koshiga may be capable of

* This paper was originally published in Japanese in J. Japan Inst. Metals, 36 (1972), 657.

** National Research Institute for Metals, Nakameguro, Meguro-ku, Tokyo 153, Japan.

Trans. JIM explaining these results phenomenologically ${ }^{(10)}$.

In this paper, in order to investigate the influence of a plastic deformation zone at the tip of a notch on the brittle fracture strength, the effect of preloading at room temperature on the fracture strength of structural steels (SM 50) at liquid nitrogen temperature was examined.

\section{Experimental}

Twenty-two $\mathrm{mm}$ thick structural steel plates were used and their chemical compositions are shown in Table 1. Standard Charpy V specimens with a central notch of $2 \mathrm{~mm}$ depth, $0.25 \mathrm{~mm}$ root radius and $45^{\circ}$ angle were machined from bars of $10 \mathrm{~mm}$ square in cross section, which were cut parallel to the rolling direction from the central part of the steel plate. The notch was cut normal to the plate.

Specimens were annealed in vacuum for $1 \mathrm{hr}$ at $670^{\circ} \mathrm{C}$ in order to remove the strain by machining and then furnace-cooled. Ferrite thus obtained were about $30 \mu$ in diameter.

Specimens were loaded by 3- or 4-point loading as shown in Fig. 1. Experiments were carried out using

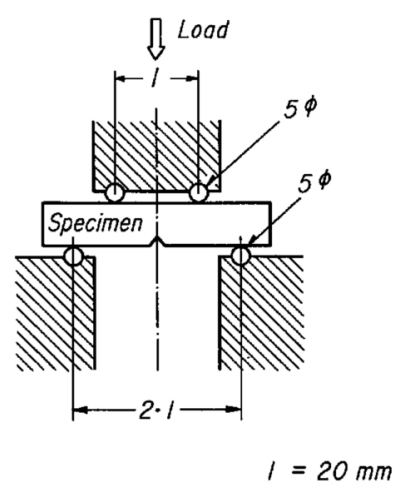

(a)

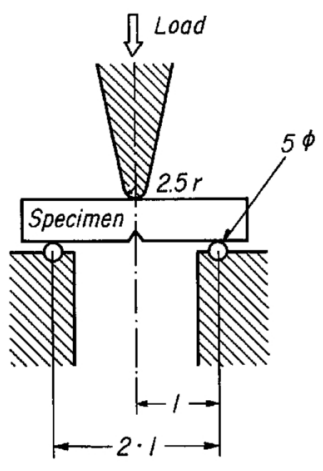

(b),
Fig. 1(a) Bending jig.

(a) 4-point loading jig (b) 3-point loading jig.

1974 Vol. 15 


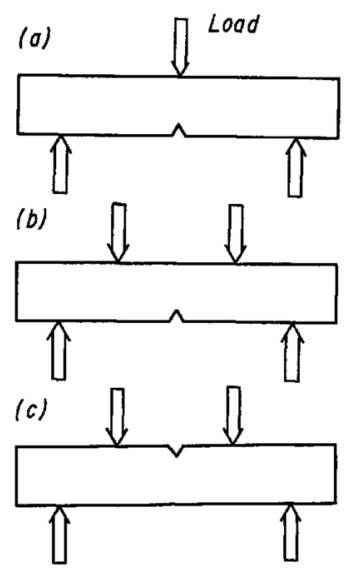

Fig. 1(b) Loading mode.

(a) 3-point loading (b) Positive 4-point loading (c) Negative 4-point loading

Table 1 Chemical composition (wt \%).

\begin{tabular}{ccccccc}
\hline \multirow{2}{*}{ Thickness } & \multicolumn{5}{c}{ Chemical composition } \\
\cline { 2 - 6 } & $\mathrm{C}$ & $\mathrm{Si}$ & $\mathrm{Mn}$ & $\mathrm{P}$ & $\mathrm{S}$ \\
\hline $22 \mathrm{~mm}$ & 0.17 & 0.31 & 1.10 & 0.03 & 0.02 \\
\hline \hline
\end{tabular}

a Instron-type universal testing machine driven at a constant cross head speed.

Specimens were preloaded up to a general yield load by 3-point, positive 4-point or negative 4-point loading (see Fig. 1(b)) and unloaded at room temperature. Then they were bent at liquid nitrogen temperature. All specimens were brittle-fractured.

\section{Results and Discussion}

Figure 2(a) shows the applied load-deflection curves by 4-point loading at room temperature. There is little difference between the curves (a) and (b) and a general yield load is not found distinctly. In this work, however, a pronounced general yield load was found in the applied load-deflection curve of specimens in the 3-point loading test (Fig. 2(b)) and the general yield load corresponded to $0.04 \mathrm{~mm}$ plastic deflection; the load corresponding to $0.04 \mathrm{~mm}$ plastic deflection was defined as a general yield load in the 4-point loading test. Photograph 1 shows the plastic deformation band near the root of a notch at the sur-

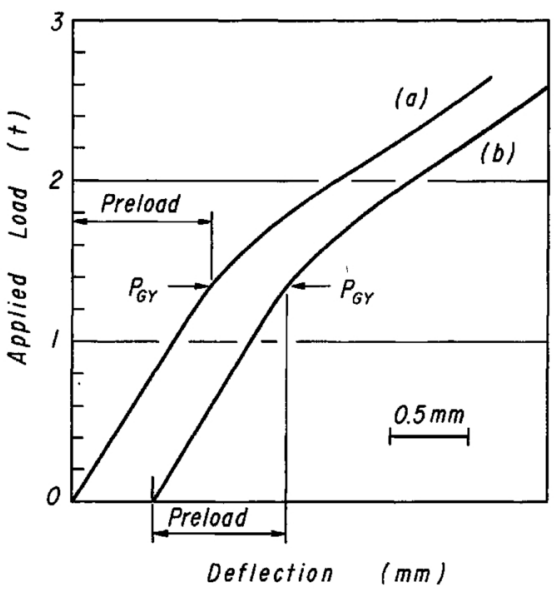

Fig. 2(a) Applied load-deflection curves at room temperature. (tested by 4-point loading, cross head speed: $2 \mathrm{~mm} / \mathrm{min}$ )

(a) positive loading (b) negative loading $P_{G Y}$ : general yield load

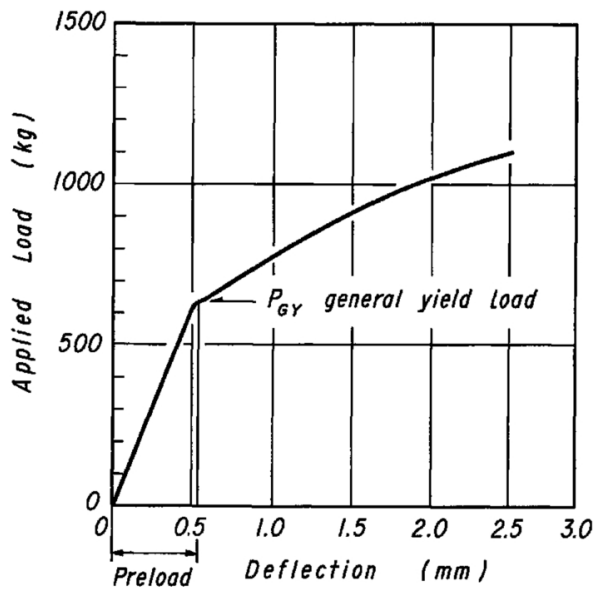

Fig. 2(b) Applied load-deflection curve at room temperature. (tested by 3-point loading, cross head speed: $2 \mathrm{~mm} / \mathrm{min}$ )

faces of specimens which were preloaded to $P$ by $4-$ point loading at room temperature. When the ratio of preload $P$ to general yield load $P_{G Y}$ is 0.96 , the size of plastic deformation band of the specimen preloaded by negative 4-point loading is nearly equal to that preloaded by positive 4-point loading. Therefore, it is assumed that there is no difference in the plastic zone size between the specimens preloaded by positive 4-point loading and the negative 4-point loading at the mid-section of the specimen. Consequently, the
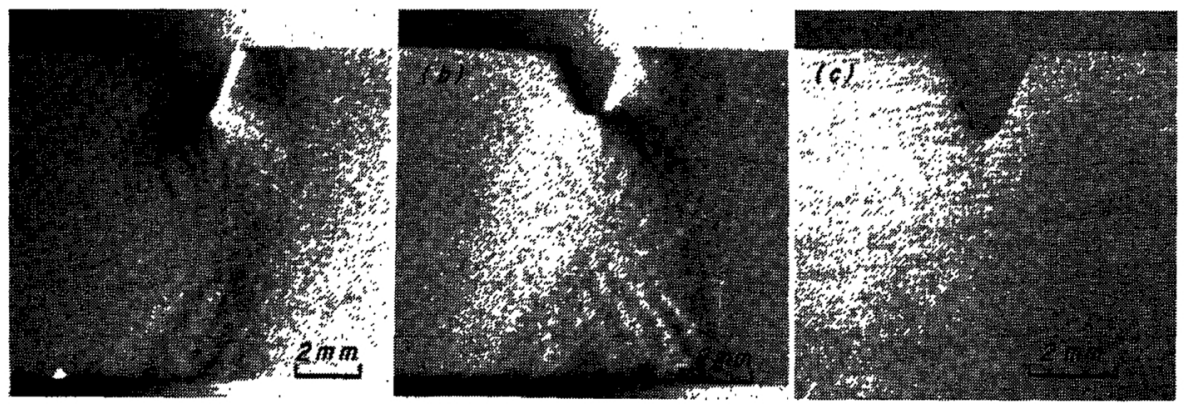

Photo. 1 Plastic zone of preloaded specimens. (preloaded by 4-point loading at room temperature)

(a) positive loading, $P / P_{G Y}=0.96$

(b) negative loading, $P / P_{G Y}=0.96$

(c) positive loading, $P / P_{G Y}=0.75$ 


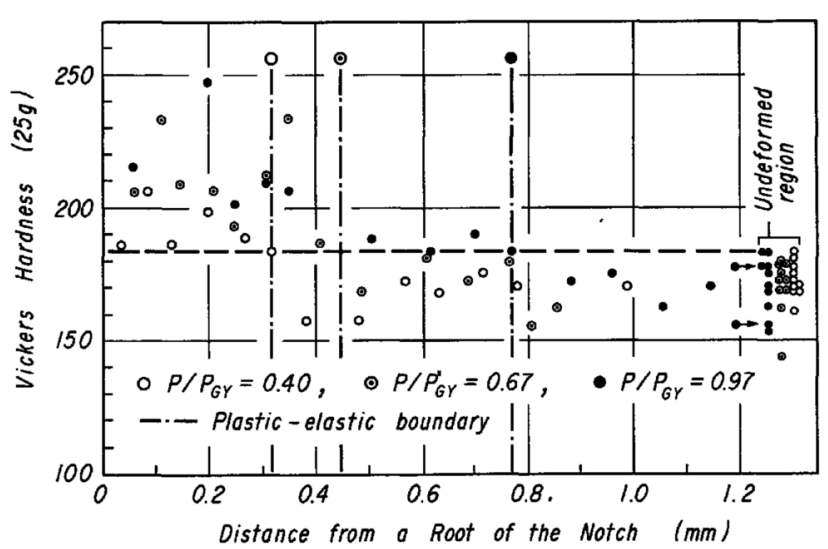

Fig. 3 Estimate of plastic zone size below the root of a notch by the Vickers hardness (loaded at room temperature by 3-point loading, cross head speed: $2 \mathrm{~mm} / \mathrm{min}$ ).

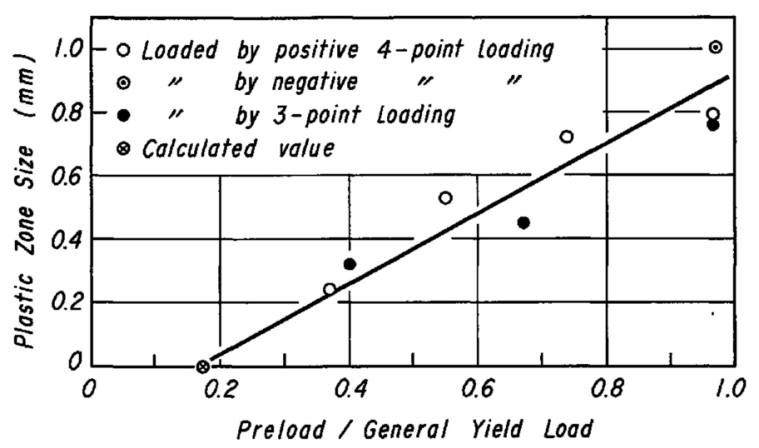

Fig. 4 Effect of preloading on a plastic zone size below the root of a notch.

plastic zone size at the mid-section of specimens seems to decrease with decreasing preload.

Although the plastic zone formed in Fe-Si steels and nitrogen-rich steels can be observed by etch pit technique $^{(1)}$, it was very difficult to reveal the plastic zone in structural steels. Thus, the plastic zone size parallel to the notch direction at the mid-section of specimens was approximately estimated by a microVickers hardness test. Namely, using a load of $25 \mathrm{~g}$, the hardness was measured only in ferrite grains. Figure 3 shows the relation between Vickers hardness and distance from the root of a notch in the specimens which were preloaded at room temperature. Here, assuming that the region where a higher hardness than that in the undeformed region is observed corresponds to the plastic zone, its size could be approximately estimated. Figure 4 shows the effect of preload on the plastic zone size at the mid-section of specimen. The plastic zone size obtained by preloading in the range of general yield load is about $0.9 \mathrm{~mm}$ and this value is comparable to those for other steels ${ }^{(1)(11)}$. The zone size of specimens does not undergo any remarkable change by 3-point loading and 4-point loading, respectively, and it increases linearly with the ratio of preload $P$ to general yield load $P_{G Y}$. The value at which the plastic zone began to appear was calculated in due consideration of stress concentration.

Figure 5 shows the dependence of the flank angle on preload. It was found that preloading does not influence the flank angle in the specimens preloaded by positive 4-point loading and negative 4-point

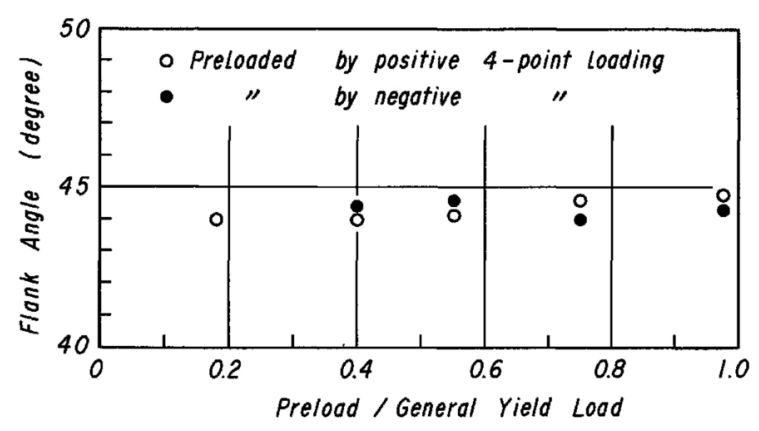

Fig. 5 Preloading dependence of flank angle.

Table 2 Effect of preloading on general yield load at liquid nitrogen temperature.

\begin{tabular}{|c|c|c|c|}
\hline Cross head speed & $P / P_{G Y}$ & $\begin{array}{l}\text { Preloading } \\
\text { mode }\end{array}$ & $\begin{array}{l}P_{G X} \text { at liq. } \\
\mathrm{N}_{2} \text { temp. }\end{array}$ \\
\hline \multirow[t]{2}{*}{$0.2 \mathrm{~mm} / \mathrm{min}$} & - & - & $3430 \mathrm{~kg}$ \\
\hline & 0.98 & Positive loading & $3450 \mathrm{~kg}$ \\
\hline \multirow[t]{2}{*}{$2 \mathrm{~mm} / \mathrm{min}$} & - & - & $3500 \mathrm{~kg}$ \\
\hline & 0.98 & Negative loading & $3500 \mathrm{~kg}$ \\
\hline \multirow[t]{2}{*}{$20 \mathrm{~mm} / \mathrm{min}$} & - & - & $3850 \mathrm{~kg}$ \\
\hline & 0.98 & Positive loading & $3870 \mathrm{~kg}$ \\
\hline
\end{tabular}

loading, respectively. The microcrack whose size was as large as ferrite grains were not observed at the root of a notch with an optical microscope. These facts indicate that the fracture test can be carried out at liquid nitrogen temperature without changing the shape of specimens in the preloading test. It is also known that the stress distribution at the root of a notch satisfies the plane strain condition at the midsection of a standard Charpy V specimen ${ }^{(1)}$. As the width of specimens at the root of a notch preloaded up to a general yield load decreased by only $\pm 0.2-$ $0.3 \mathrm{~mm}$, the stress distribution at the root of a notch for preloaded specimens seems to satisfy the plane strain condition.

In order to examine the effect of preloading at room temperature on the general yield load at liquid nitrogen temperature, the specimens were preloaded to $P_{G Y}$ by positive or negative 4-point loading and then bent at liquid nitrogen temperature by negative 4-point loading. The results are shown in Table 2 . There is no difference between the annealed and the preloaded specimens, but an effect of deflection rate (cross head speed) on the general yield load was found.

Figure 6 shows the effect of preloading on the fracture load at liquid nitrogen temperature. In this case, the specimens were preloaded by positive or negative 4-point loading and then fractured by positive 4-point loading. Cross head speeds were $0.2,2,20 \mathrm{~mm} / \mathrm{min}$. When specimens were preloaded by positive 4-point loading, no change of fracture load was found at small preload. At larger preload, the fracture load increased with $P / P_{G Y}$, approaching a definite value. When the specimens were preloaded and then fractured by 3point loading, a similar trend to that mentioned above was observed. Meanwhile, when the specimens were preloaded by negative 4-point loading, the fracture load was almost independent of the preload given. The fracture load lowered as the cross head speed 


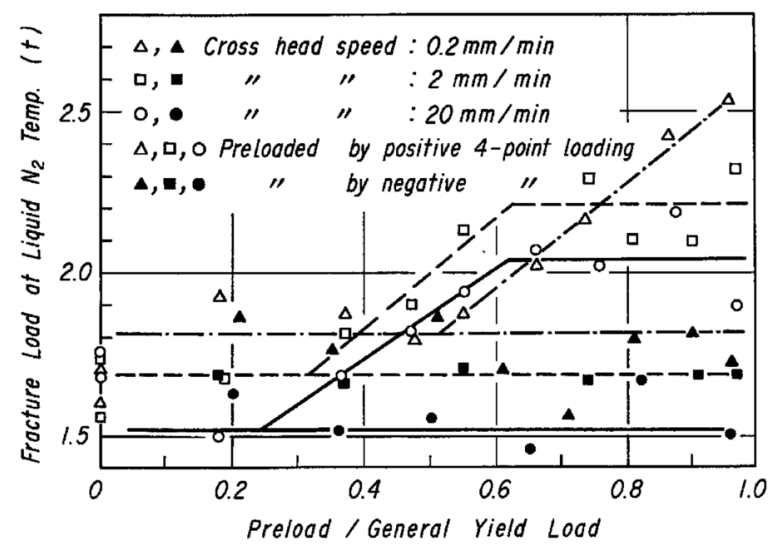

Fig. 6 Effect of preloading on fracture load at liquid nitrogen temperature. (tested by positive 4-point loading)

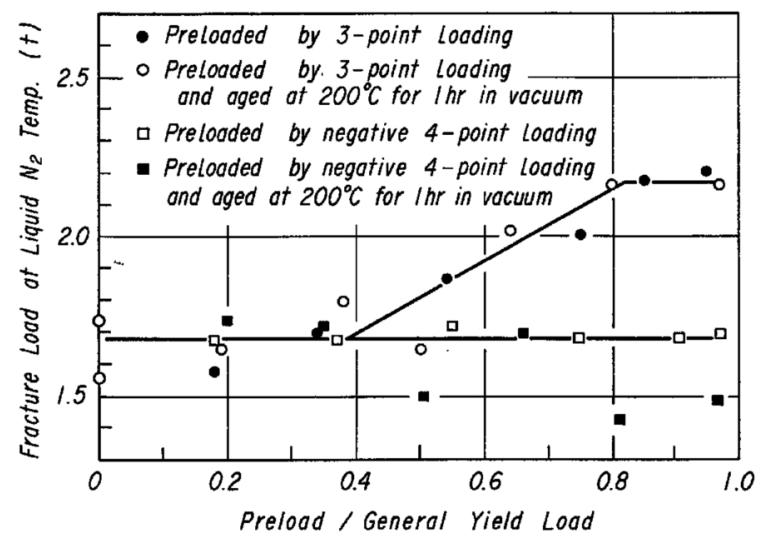

Fig. 7 Effect of strain ageing at $200^{\circ} \mathrm{C}$ on fracture load. (tested by positive 4-point loading, cross head speed: $2 \mathrm{~mm} / \mathrm{min}$ )

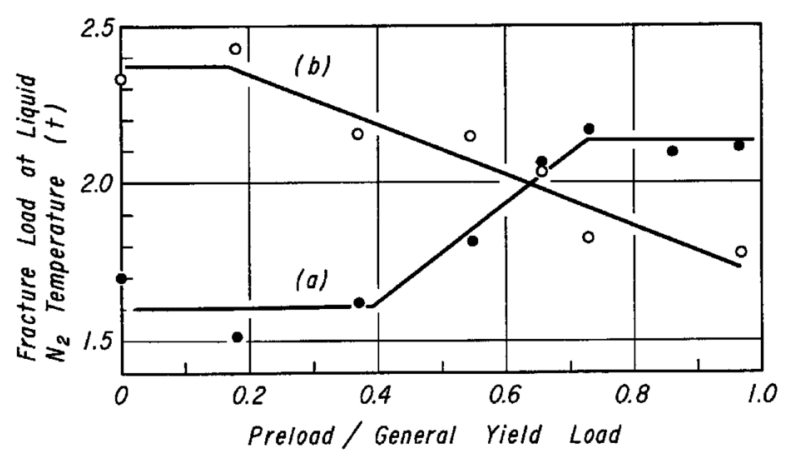

Fig. 8 Effect of preloading on fracture load. (tested by positive 4-point loading, cross head speed: 2 $\mathrm{mm} / \mathrm{min}$ )

-: preloaded by negative 4-point loading $\left(P / P_{G Y}=0.98\right)$, and then by positive 4point loading

$O$ : preloaded by positive 4-point loading $\left(P / P_{G Y}=0.98\right)$, and then by negative 4point loading

increases, and the $P / P_{G Y}$ where the fracture load began to be subject to preloading became smaller. In no case did the previous works ${ }^{(6) \sim(9)}$ prove that the fracture load is not affected by negative 4-point preloading and that the dependence of the fracture load on positive 4-point preloading is influenced by the cross head speed.

Figure 7 shows the influence of strain aging on fracture load. Specimens were aged at $200^{\circ} \mathrm{C}$ for $1 \mathrm{hr}$ after preloading. In both of the specimens preloaded by 3-point loading and negative 4-point loading, the effect of strain aging was not seen distinctly.

In Fig. 8, the curve (a) shows the relationship between fracture load and re-preload for the specimens which were preloaded to $P_{G Y}$ by negative 4-point loading and then preloaded by positive 4-point loading. Curve (b) shows a similar relation to the curve (a) when the specimens were preloaded to $P_{G Y}$ by positive 4-point loading and moreover preloaded by negative 4-point loading. The fracture load-preload curves have a tendency similar to those in Fig. 6 for the specimens which were re-preloaded by positive 4-point loading, irrespective of whether or not preloading is given by negative 4-point loading. Nevertheless, the specimens preloaded by positive 4-point loading are influenced by negative 4-point re-preloading, and the effect of preloading by positive 4-point loading on fracture load seems to be removed by negative 4-point re-preloading.

For rigid perfectly plastic materials, the longitudinal stresses along the net section within the plastic zone near the root of a notch $(x \leqq R)$ was given by Hill(12) (see Fig. 9):

$$
\begin{array}{lc}
\sigma_{y y}=\sigma_{Y}\{1+\log (1+x / \rho)\}, & \left(x \leqq R_{\beta}\right) \\
\sigma_{y y}^{\max }=\sigma_{Y}\{1+\pi / 2-\omega / 2\} . & \left(R_{\beta} \leqq x \leqq R\right)
\end{array}
$$

These equations were introduced on the basis of Tresca's yield criterion, where $x$ is the distance parallel to the $\mathrm{x}$ axis from the root of a notch, $\rho$ the notch root radius, $\omega$ the flank angle, $\sigma_{Y}$ the uniaxial yield stress when a specimen is deformed at the same strain rate as that at the root of a notch, $R$ the plastic zone size from the root of a notch, $\sigma_{y y}^{\max }$ the maximum longitudinal stress only depending on $\omega$ and $R_{\beta}$ the distance from the root of a notch when $\sigma_{y y}$ takes the maximum stress, $\sigma_{y y}^{\max }$.

When the specimens are preloaded to a general yield load, their bending angle is found to be small. So, the nominal stress $\sigma_{n}$ at the root of a notch is given by

$$
\sigma_{n}=6 \mathrm{M} /\left(t a^{2}\right),
$$

where $a$ is the depth of the notched cross section of a specimen, $t$ the width of a specimen and $M$ the applied bending moment. It is known that the relation between the general yield stress $\sigma_{G Y}$ and the uniaxial yield stress $\sigma_{Y}$ can be given by ${ }^{(13)}$

$$
\sigma_{G Y} / \sigma_{Y}=L
$$

where $L=1.26$ for $\omega<60^{\circ(14)}$. Using eqs. (1)-(4), the longitudinal stress within the plastic zone at the root of a notch during preloading can be obtained (Fig. 9). Here, the relationship between load/general yield load and plastic zone size $R$ in Fig. 4 is used. When $P / P_{G Y}=0.68$, the longitudinal stress is found to take the maximum value, about $108 \mathrm{~kg} / \mathrm{mm}^{2}$. Compared with the preload dependence on fracture load at various cross head speeds in Fig. 6, it seems that the stress distribution in the plastic zone at the root of a notch during preloading does not directly influence the fracture load at liquid nitrogen temperature. 


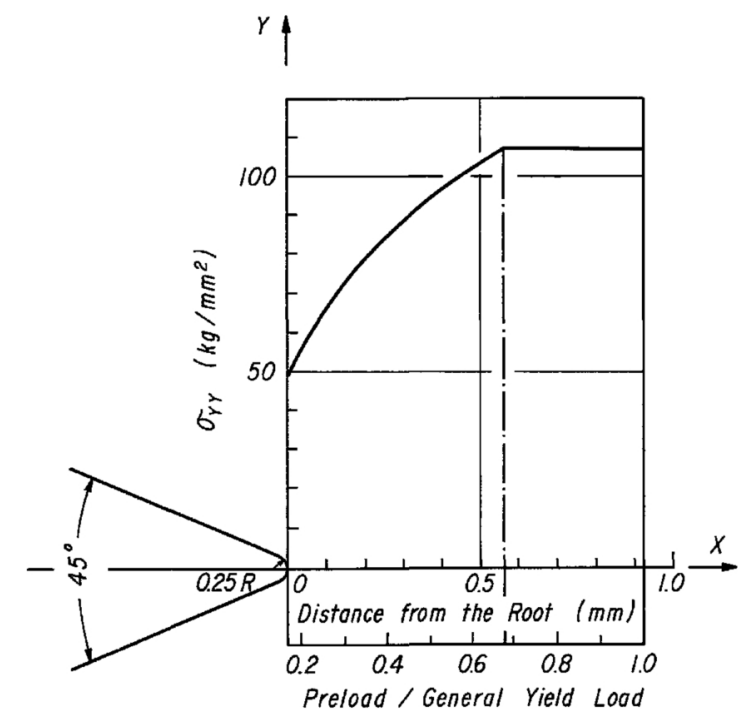

Fig. 9 Stress distribution in a plastic zone below the root of a notch.

When the specimens are preloaded to form the plastic zone near the root of a notch, and then unloaded, the longitudinal stress remains at the root. Both values of the residual stress and the size of the region where it exists are thought to increase with the plastic zone size, that is, $P / P_{G Y}$. The residual stress produced by negative 4-point loading is a tensile one. In Fig. 6, the dependece of fracture load on preload at liquid nitrogen temperature changes with cross head speed, and the fracture load is nearly constant in the specimens preloaded by negative 4-point loading. It appears therefore that the effect of residual stress at the root of a notch on the fracture load cannot be deduced in a simple form.

The effect of preloading on fracture strength is introduced by the macroscopic residual stress at the root of a notch, which is caused by the plastic deformation zone produced by preloading. The residual stress is superimposed on applied tensile stress. The compressive residual stress decreases applied stress, and the tensile residual stress raises the applied stress. The effect causes the specimens preloaded by positive loading to increase the fracture load and the specimens preloaded by negative loading to decrease it.

According to the $\rho^{+}$concept proposed by $\operatorname{Koshiga}^{(10)}$, the plastic deformation zone at the root of a notch is decreased by the compressive residual stress, when the specimens are subjected to applied load. As the critical plastic deformation zone (or yielded zone) necessary to fracture is obtained from the increased applied load, the fracture load is thought to be increased by preloading. The tensile residual stress is thought to decrease the fracture load. However, as the plastic deformation zone is small and the stress concentration factor is relatively small for the specimens used in the experiment, the effect of residual stress should be small, and this effect seems to be influenced by the plastic deformation at the root of a notch. As shown in Fig. 6, the specimens preloaded by negative 4-point loading does not show the dependence of fracture load on preload. Therefore, it can be said that the plastic deformation zone at the root of a notch introduced by preloading not only produces the macroscopic residual stress, but also has the effect in itself to increase the fracture load. In the specimens preloaded by positive 4-point loading, the fracture load is thought to be increased by the plastic deformation zone itself as well as compressive residual stress at the root of a notch. It can also be seen in Fig. 8 that the fracture load is not only influenced by residual stress but also increased by the plastic deformation zone at the root of a notch. Details of the effect of the plastic deformation zone at the root of a notch and the saturation of fracture load at large $P / P_{G Y}$ will be described elsewhere ${ }^{(15)}$.

\section{Conclusions}

The influence of preloading at room temperature on fracture load was examined on specimens which were brittle-fractured at liquid nitrogen temperature, using standard Charpy V-notched specimens of structural steels (JIS SM 50), of which the stress concentration factor is relatively small. The following results were obtained.

(1) When the compressive residual stress remains at the root of a notch after preloading, the fracture load was influenced by preloading. That is, the fracture load was not affected by a small amount of preload, but it increased with a further increase in preload, approaching a definite value. This tendency was also found in the cases where specimens were aged at $200^{\circ} \mathrm{C}$ for $1 \mathrm{hr}$ and when the cross head speed was changed.

(2) When the tensile residual stress remains at the root of a notch after preloading, the fracture load was not affected by preloading. The fracture load was independent of preload and had a nearly constant value. This tendency was also obtained in the cases specimens were aged at $200^{\circ} \mathrm{C}$ for $1 \mathrm{hr}$ and when the cross head speed was changed.

These results indicate that the fracture load at liquid nitrogen temperature should be influenced by the residual stress, the plastic deformation zone and the internal condition at the root of a notch after preloading rather than the stress condition at the root of a notch during preloading.

\section{Acknowledgment}

The author wishes to express his sincere gratitude to Dr. K. Iwamoto, the former head of the material strength research division, National Research Institute for Metals, for his stimulating discussions.

\section{REFERENCES}

(1) T. R. Wilshaw and P. L. Pratt: J. Mech. Phys. Solids, 14 (1966), 7.

(2) B. A. Bilby, A. H. Cottrell and K. H. Swinden: Proc. Roy. Soc. London, A272 (1963), 304.

(3) B. A. Bilby, A. H. Cottrell, E. Smith and K. H. Swinden: Proc. Roy. Soc. London, A279 (1964), 1.

(4) B. A. Bilby and K. H. Swinden: Proc. Roy. Soc. London, A285 (1965), 22.

(5) A. A. Wells: Brit. Weld. J., 10 (1963), 563. 
(6) E. A. Steigerwald: Trans. ASM, 54 (1961), 445.

(7) A. J. Brothers and S. Yukawa: Trans. ASME, 85D (1963), 97.

(8) H. Kihara, K. Masubuchi, K. Iida and H. Oba: I. I. W. Doc., X-218-59.

(9) R. W. Nichols: Brit. Weld. J., 15 (1968), 21.

(10) F. Koshiga: I. I. W. Doc., X-566-70.

(11) J. R. Griffiths and G. Oates: Proc. 2nd Int. Conf. on
Fracture, Brighton, (1969), p. 229.

(12) R. Hill: Mathematical Theory of Plasticity, Oxford, London, (1950).

(13) G. Lianis and H. Ford: J. Mech. Phys. Solids, 7 (1958), 1.

(14) A. S. Tetelman and A. J. McEvily, Jr.: Fracture of Structural Materials, John Wiley and Sons, New York, (1967), p. 301.

(15) M. Nakamura and K. Tsuya: to be published. 